\title{
Staff Motivation: Critical Analysis to Create Effective Working Environment
}

\author{
David Benders \\ Union College, Educational Studies Unit, Barbourville, KY 40906, United States of America \\ *Corresponding Author: dbenders@unionky.edu
}

Copyright (C) 2013 Horizon Research Publishing All rights reserved.

\begin{abstract}
This analysis of previous research examines staff motivation and the influence on effective organizational growth. This critical analysis of Motivation-Hygiene Theory by Fredrick Herzberg examines opportunity areas for improvement of administration to create an effective working environment that supports its teachers. The findings from the literature claim that a good working environment is encouraging and this will lead to higher performance and job enrichment.
\end{abstract}

Keywords Staff Motivation, Motivation Hygiene Theory, Higher Performance

\section{Introduction}

A vital factor in attaining organizational effectiveness is the management of the human resource. Nowhere is this factor more crucial than in our schools, where the kind of education that children receive is so heavily dependent on the quality of the performance of the teachers who staff them - quality defined not only in terms of teachers' knowledge and skill but also in terms of their dedication to teaching and the strength of their motivation to attain high levels of performance. The problem of motivating staff is a perennial one, ever since organized activity began, organization have been confronted with the problem of motivating employees to move toward full commitment to organizational goals. This paper examines the implication for educators of the "Motivation-Hygiene Theory" proposed by Frederick Hertzberg and proposes some strategies for developing staff motivation.

\section{Discussion}

The work of Herzberg indicates that factors which result in job satisfaction are directly related to work performance, and factors which result in job dissatisfaction tend to be related to the job environment. "Environment conditions which surround the doing of a job do not have the potentiality to give men basic satisfaction." (Hertzberg, 1959, 154)

It is only from the job itself that the employee can gain "the reward that will reinforce his aspiration". Hygiene's act in a manner analogous to the principle of medical hygiene. Just as medical hygiene operate to remove health hazard from our environment, so these "hygiene's" operate to remove dissatisfaction hazard from the work environment. Herzberg suggests that factors which are source of job satisfaction and those which contribute to job dissatisfaction do not belong to the same conceptual continuum. He hypothesized that satisfaction factors and dissatisfaction factors are basically different and mutually exclusive: "that some factors are satisfiers when present but not dissatisfiers when absent: other factors are dissatisfiers, but when eliminated as dissatisfiers do not result in positive motivation". (Hertzberg, 1959, 144)

The problem of motivating staff does not admit of an easy solution applicable to all teachers and all tasks." The first and most important thing to be said about motives is that everybody has a lot of them and that nobody has quite the same mixture as anyone else". (Gellerman, 1963, 155)

One is inclined to agree with him when he suggests that there are people "Who work chiefly for money, others who work chiefly for security and still others who work because they enjoy it: there are even those who work chiefly because they wouldn't know what to do with themselves otherwise". (Gellerman, 1963, 175)

So the administrator has to deal with human diversity "regardless of whether he finds it administratively convenient or conceptually easy to grasp." (Gellerman, 1963, 175)

Hertzberg claims, however, that it can be argued that there is sufficient homogeneity within various groups of employees to make for relative similarity of "needs" hierarchies within each group. If this is so perhaps it is possible to discover strategies that are likely to satisfy these needs and provide motivation for at least the majority of staff.

It would appear also that the theories mentioned have implications for the "leadership behavior" of the administrator. Considerable theoretical and empirical work 
on leadership suggests that the behavior of leaders can be categorized into two distinct types: that which is task oriented, and that which is person oriented. It is generally accepted that these two orientations are not at either end of a conceptual continuum but are actually two separate continua or dimensions. Both types of leader behavior appear to be important in affecting the motivation of subordinates. To the extent that the administrator is task oriented, he is likely to set goals for teacher performance and to make explicit the rewards and punishments that will result from various behavioral outcomes; to the extent that he is person oriented, he is likely to attempt to provide as many rewarding situations as possible and in a manner that will be seen by teachers as supportive.

Effective leadership is generally associated with high performance on both dimensions. (Halpin, 1967) "Teachers tend to express a preference for the integrated style which combines both initiating structure and consideration". (Sergiovanni, 1967, 62)

\section{Strategies for Developing Staff Motivation}

Three major areas will be considered as appropriate in developing these strategies. In brief, the administrator should aim at:

1. Increasing his staff's degree of control over their working world, (i.e. Providing his staff with the opportunity of setting their own goals).

2. Providing his staff with the opportunity for participative decision making.

3. Increasing the professional competence of his staff, through in-service training, so that they will be more informed as decision-makers.

\section{Staff Control over Work (Goal Setting)}

The employee "must be given responsibility, authority and increased control over the decision making that affects his immediate environment. He must become self-responsible". (McGregor, 1960)

This conception of job enlargement is similar to Hertzberg's notion of the job enrichment.

By job enrichment, Hertzberg means "loading" jobs with the "motivators", i.e., building into the design of jobs high amounts of responsibility, clear-cut opportunities for advancement and specific recognition for performance. The assumption is that if jobs are redesigned in this way, performance will be increased because employees will "want" to do a good job. They will want to do a good job, according to Hertzberg, because they have a chance to gain recognition, to experience growth, in short, to gain satisfaction from the performance of the job. As a way of enlarging jobs to satisfy his criteria for job enlargement

The idea of teachers having a certain degree of control over the setting of goals is an important one. Perhaps the most effective means of motivating and the most effective way of influencing teachers is to secure their commitment to the goals of the school organization. Establishing a teacher buy in with the goal setting approach creates a personal connection with the teacher and the school goal.

"If an individual identifies with an organizational goal, and accepts it, at least in part, as his own goal, the achievement of the goal becomes a source of satisfaction to him." (Miklos, 1967, 225)

"If an organization is to gain the commitment of its members and motivate them toward organizational goal achievement it must offer them not only economic rewards but also recognition and status, a sense of achievement and opportunities for realizing various individual goals." (Miklos, 1967, 225)

These are basically the satisfiers that have been referred to before in this paper. The administrator's role as motivator includes attempting to bring closer together these two dimensions of organizational expectations and individual needs. To do this he might have to develop a "transactional" style of leadership. He sees the need for making clear the nature of the organizational roles and expectations, but he also attempts to structure institutional action so as to provide for individual fulfillment. It would appear, therefore, that the administrator should involve staff in the setting of goals and objectives for the school. This would include participation in the formation of general goals statements for the school as well as the more specific curriculum and institutional objectives. This should in turn lead to greater commitment to goal achievement by teachers and consequently greater job satisfaction.

\section{Staff Participation in Decision-Making}

Closely associated with the granting to teachers of greater control over their work is the strategy of participative decision making. Research evidence suggests that teacher participation in decision making has desirable consequences.

"Teachers who report opportunity to participate regularly and actively in making policies are much more likely to be enthusiastic about their school systems than those who reported limited opportunity to participate." (Chase, 1952, 67)

"A direct relation between teachers' satisfaction and the extent to which they participate in decision making." (Sharma, 1955, 5) "Regardless of whether teachers had a high or low need for independence, they preferred principals who involved their staff in decision making."'(Bridge, 1967, 41)

Such studies suggest that participation in decision making increases a teacher's level of satisfaction, his enthusiasm for 
his school system and his positive attitude towards his principal. Should the administrator decide to implement this strategy, he must consider such questions as: on what issues will he seek staff involvement? Which of the staff will he involve? To what degree should he involve them? At what stage in the decision-making process should he involve them? In considering these questions he should be aware that there may be certain areas in which particular staff members, or the staff as a whole, are keenly interested. There are others that fall within what Barnard28 terms their "zone of difference". That is, these areas do not concern them greatly, they want no part in making decisions on such issues, and they will accept, without question, the principal's decision on such matters. Two rules of thumb for administrators to use in identifying decisions in which teachers will want to share (Bridges, 1967):

1. The test of relevance. Does the decision involve areas of the school that will have a direct effect on the teacher?

2. The test of expertise. Does the teacher have the expertise to make the decision?

3. The test of jurisdiction. Does the teacher have a position of authority, within the hierarchical school, or school system structure to make the decision? (Owen,1970)

Having decided which of the staff to involve, and in which decisions to involve them, the administrator will be concerned with determining the stage in the process at which he desires staff involvement. The teacher's area of freedom depends largely on the administrator's decision in these matters. He can expand or restrict teachers' area of freedom by involving them in earlier stages or later stages of the process, as well as expanding or diminishing the degree of involvement in each stage. This motivational strategy of participative decision making is in this sense firmly in the administrator's control.

\section{Staff in-Service Training - Increasing Professional Competence}

If staff is to make informed decisions, they must be professionally competent and informed. Once they have been appointed to schools their professional competence can be improved by means of In-service Training, through agencies outside the school and also through agencies within the school. "Satisfaction among teachers results from achievement, recognition and responsibility." (Sergiovanni, 1975, 74)

Factors related to achievement which are considered important by satisfied teachers are "Learning new things", "Innovative methods of training" and "Opportunity for in-service education". The three primary goals of in-service programs are (Sergiovanni, 1975, 75);

(1) Providing information which helps educators keep abreast of current developments.

(2) Providing opportunities for the improvement of professional skills.

(3) Changing attitudes, behaviors, and motives of educational workers they stress that the last goal — which they suggest is the most important one - receives the least amount of support from educators.

The administrator can encourage teachers to become involved in the professional development committees of their professional organization. "He can act as a "Resource Linker" in bringing in outside experts and authorities in the field of education. He can make use of the expertise of particular teachers who can be encouraged to demonstrate their abilities, in particular subject areas, to other staff members."(Havelock, 1973)

Allowing teachers to exchange classes for specified periods can have a positive effect on a teacher's professional development, as can permit teachers to visit other professionals both in their own school and other schools. Use can be made of consultants and other resource people, and follow-up discussion sessions held. Simulation techniques, such as "In-basket" exercises and case studies which raise problems relevant to the particular school may also prove useful. Encouraging workshops, instructional committees and professional reading are other suggestions for the administrator.

Further, he can pass on to staff, individually and in groups, the benefit of his experience in the classroom. This can be done formally, in group meetings and in the classroom, or informally and incidentally. It becomes somewhat difficult in large schools where the demands of the office tend to lessen the direct involvement of the administrator in the classroom. There is also a limitation, nowadays, in that the administrator can no longer be "master teacher" in all the subject areas and he may feel uncomfortable making suggestions outside his area of expertise. Nevertheless it is an area of potential influence and motivation that an administrator should be aware of and act upon.

In his role of fostering the professional development of teachers the administrator must make full use of his "expert" and "referent" power.(Raven,1968) Influence based on his expertise and on good relationships between him and his staff will prove to be a most potent factor in implementing the strategy of developing his staff's professional competence.

Of course, individual teachers differ. Therefore the strategies which have been mentioned as likely to motivate staff, by providing them with a sense of achievement, with recognition for their work effort and with responsibility for their work and control over objectives, will not motivate all teachers. All teachers do not have a strong need to achieve "selfactualisation" on the job. While the theory suggests that for the most part only the "satisfiers" motivate, it would be incorrect to conclude that some people are not motivated by the dissatisfiers. For example, one of the findings of a study examining the extent to which teachers displayed motivation-seeking tendencies as opposed to hygieneseeking tendencies was that "two-thirds of the respondents were motivation-seekers, one-fourth were hygiene-seekers, with the remaining 8 percent falling midway between the two orientations.”(Sergiovanni, 1969, 69) 
Nevertheless, the opportunity for all to experience self-fulfillment in their teaching job ought to be provided. The key word is "opportunity". It ought to be an opportunity for staff to have their jobs "enriched" rather than a demand that they change their present work style. Many teachers do have a need to "self-actualize" on the job. They will grasp the opportunity with both hands. Some poor performances will remain as before, but nothing is really lost. If the motivating strategies used are opportunities rather than demands, then the less able or those less willing to take the opportunities will ignore them or not even recognise them. Some teachers, however, will develop as they never could have under conditions where the motivators, achievement, recognition and responsibility were not operating.

\section{Conclusion}

Motivating teachers to teach is not the fundamental challenge for administrators according to Herzberg, it's the dissatisfied environment in the school where learning is taking place. The Herzberg's model attempt to address the collective empowerment and ownership of the school objectives and those of the teacher it create a working relationship that will flourish.

The three areas of motivation by Herzberg foster ownership and collaboration. Even given today's climate of standardization, teacher ownership is achievable. Allowing teachers to feel a part of the planning process creates an environment of partnership and motivation to achieve.

Examining the classroom of your teachers you will see they have already adopted these models in a standardize world, as they attempt to get their students to buy into the annual academic goals. Students will set their own incremental goals throughout the year. The teachers' create individualize learning strategies based on the need areas of the students. This helps with the student decision making process apart of the goals for the student and how to attain those goals. And finally, students are given supplemental training only on those need areas related to them meeting their academic goals. Teachers identify and recommend students to supplemental resource teachers to provide extra help in key academic areas. These strategies result in higher motivation of both student and teacher within the classroom learning environment.

The challenge for the administrators lie in re-examining the necessity and usefulness of practices which have never been seriously questioned because they were presumably indispensable, especially with regard to organization and supervisory methods. It lies in discovering practical ways of releasing the energy and creativity that now seem to be suppressed in many apparently apathetic employees.(Gellermen,1963, p.293).

\section{REFERENCES}

[1] Herzberg, F., Mausner, B. and Snyderman, B.1959, The Motivation to Work. New York.Wiley. Maslow. A.1954, Motivation and Personality. New York. Harper. McGregor, D.1960, The Human Side of Enterprise. New York. McGraw-Hill. Sergiovanni, J.1967, "Factors Which Affect Satisfaction and Dissatisfaction of Teachers" Journal of Educational Administration. 5. pp. 66-82.

[2] Sergiovanni, J. and Carver, F.D.1973, The New School Executive: A Theory of Administration. New York. Dodd, Mean \& Co.

[3] Gellerman, S.W (1963), Motivation and Productivity. New York. Vail-Balou.

[4] Katz, D. and Kahn, R.L. (1966), The Social Psychology of Organizations. New York. Wiley.

[5] Halpin, A, (1967), Theory and Research in Administration. New York. Macmillan, Fiedler, F. A Theory of Leadership Effectiveness. New York. McGraw-Hill. 1967.

[6] Sergiovanni, R. and Starratt, R.J.1971, Emerging Patterns of Supervision: Human Perspectives. New York. McGraw-Hill.

[7] Argyris, C. Integrating the Individual and the Organization. New York. Wiley. 1964.

[8] Argyris, C. Personality and Organization. New York. Harper and Row. 1957.

[9] Miklos, E. The Setting for the Principalship. Alberta Principals Leadership Course. 1967.

[10] Likert, R. The Human Organization. New York. McGraw-Hill. 1967.

[11] Chase, F. (1952) cited in Bridges E.M. "A Model of Shared Decision Making in the School Principalship" Education Administration Quarterly. 4. 1967. pp. 47-61.

[12] Sharma, C. "Who Should Make What Decisions?" Administrator's Notebook. 111. 1955. pp. 1-5.

[13] Bridges, E. "A Model of Shared Decision Making in the School Principalship" Education Administration Quarterly. 4. 1967. pp. 47-61.

[14] Barnard, C. The Functions of the Executive. Cambridge. Howard University Press. 1938.

[15] Owens, R.G. Organizational Behavior in Schools. Prentice-Hall, Englewood Cliffs, N.J. 1970.

[16] Buja, R. "The Task Force - A Strategy for Educators" Challenge. 1. 1971. pp. 1-10.

[17] Havelock, R.G. The Change Agent's Guide to Innovation in Education. New Jersey, Englewood Cliffs. Educational Technology Publications. 1973.

[18] French, J.R. and Raven, B. cited in Cartwright, D. and Zander, A. Group Dynamics, Research and Theory. New York. Harper and Row. 1968.

[19] Sergiovanni, T., Mitzeus, R. and Burden, L. "Toward a Rationalistic Approach to Leadership Style: Some Findings" American Educational Research Journal. 1. 1969. pp. 62-79. 